\title{
Social Innovation with Open Source Software: User Engagement and Development Challenges in India
}

\begin{abstract}
A diverse range of innovative solutions based on Free-and-Open-Source Software (FOSS) have been developed for marginalized communities in developing countries. It has been suggested that such small-scale and home-grown solutions (e.g. smart phone apps), usually championed by social enterprises (SEs), are more likely to introduce propoor change than infrastructure heavy ICT initiatives designed by state and other international actors for meeting development targets. In the Indian context, FOSS-based social innovations (SIs) introduced by SEs are helping communities of the poor tackle previously thought-to-be unresolvable socio-economic problems. An interesting question, therefore, would be: in what ways is the SE model and approach uniquely equipped to develop FOSS-based SIs that deliver tangible results? The empirical component of the research attempts to shed light on this question by uncovering the nuts and bolts of the development methodology deployed by an SE during the coding and launch of an FOSS-based SI. Findings highlight the significant role of the founder's social vision; the challenges of accurately capturing and translating to software developers the nature and nuance of social problems; and, the incumbent issues in putting together a methodology that creates active user engagement throughout the software development process, overcoming difficult barriers such as language and culture.
\end{abstract}

Key words: Social Change, Social Innovation, Free Software, Open Source Software, Technology Policy, ICT, Developing Country, India 


\subsection{Introduction}

There has been great optimism and financial outlay for ICT projects in DCs (Heeks \& Kenny, 2000) for the purpose of introducing pro-poor change through better access to the information society (Toffler, 1980). Despite the promise of ICT for development, the literature highlights many examples of failed ICT projects with development goals. While some of these projects may have been supported by a development rationale (Madon, 2000; Mansell, 1999), such as the harmonization of price differentials and creation of demand for social inclusion and uplift; there is limited empirical evidence of ICTs positively affecting development in poor nations (Eggelston et al., 2002). In a recent review of global poverty, Alkire et al., (2015) report that South Asia is home to $52-65 \%$ of the bottom billion of which India alone accounts for over $37.5 \%$. With about 1.2 billion, or over $20 \%$ of the world's population living in absolute poverty, doubts are often raised as to whether the capabilities of ICTs can really be harnessed for development (Heeks \& Foster, 2013).

Despite the above scepticism, innovation and technology policy actors in DCs place considerable emphasis on ICTs to promote economic and social development (WBI, 2009) through the creation of efficient innovation systems (Nelson \& Winter, 1982). Here, policy actors usually hold the belief that ICTs can enable the "leap frogging" of entire stages in development, thereby, bridging the so-called "digital divide" (Norris, 2001). This has been quite difficult to achieve in practice as low and middle income countries continue to stagger behind in measurements of their innovation systems' effectiveness (Cornell University, INSEAD, and WIPO, 2013) and only modest progress has been made by such countries in the achievement of the millennium development goals (Center for Global Development, 2015).

Even though ICTs' promise of leap frogging stages of development has not fully materialized; the enthusiasm for their potential is still strong. The rapid pace of change in today's information society has created possibilities for a redefinition of the 'ICTs for development' discourse. It is being suggested that the use of ICTs for development, dubbed ICT4D, is moving from the older version 1.0 to a new version 2.0. Where ICT4D vr.1 marginalized the poor, allowing a supply-driven focus, ICT4D vr.2 centralizes them, creating a demand-driven focus. While vr.1 - fortified by the "bottom 
of the pyramid" concept (Ramani \& Mukherjee, 2014; Silvestre \& Silva Neto, 2014; Hall et al., 2014; Prahalad et al., 2009) characterized the poor largely as passive consumers, vr.2 sees them as active producers and innovators (Heeks, 2008). Evidence suggests that solutions developed under the ICT4D vr.2 worldview, which place central emphasis on requirements of the poor by enabling them to participate in the design process as active innovators, have had much greater success in changing circumstances of target groups than top-down and centrally planned ICT initiatives for promoting general economic development and poverty alleviation (Moseson et al., 2015; Yildrim \& Ansal, 2011; Eggleston, 2002; Avgerou, 2008).

It is suggested that the ICT4D vr.2 worldview is best operationalized when social innovations (SIs) are championed by social entrepreneurs or enterprises (SEs) and are enabled by the principles of free and open source software (FOSS). Here the interrelatedness and conceptual harmonization between the triad of SIs-SEs-FOSS would be crucial. SIs are novel solutions to a social problem for which the value created accrues primarily to society as a whole rather than private individuals (Phills et al., 2008). SEs undertake entrepreneurial activity with an embedded social purpose (Austin et al., 2006); operationalized through discovering, defining, and exploiting opportunities in order to enhance social wealth (Zahra et al., 2009). While FOSS is software that allows its users freedom to run, distribute, study, change and to make improvements to it where access to the source code is a necessary precondition (Free Software Foundation, 2015).

It is proposed that an important but understudied link exists between SIs, SEs and FOSS; and, understanding the nuances of this link will be important for advancing new theory in the ICT4D vr.2 discourse. To advance theory, it is believed that as a first step, an in-depth investigation to uncover the processes that SEs adopt to develop SIs under FOSS principles ought to take place. In the empirical component of this research, results of such an investigation are detailed, keeping the software design and development methodology central to contributions.

The paper is organized as follows: first, a theoretical background is presented which explores (a) the relationship between social innovation and development, (b) FOSS and its impact on DCs, and (c) the role of social enterprises and user centred approaches to 
deliver social innovation. Second, a justification for the choice of country, site and specific case are presented; also highlighted are the research's aim, philosophical lens, and data collection and analysis approaches. Next, case data from the research is presented which describes the processes of development, launch and uptake of an FOSS-based software solution developed by a SE. The following discussion section pulls together the major findings and contributions from the research, where a number of theoretical propositions are put forth. Finally, in the conclusion section, final thoughts on the value of the research are put forth and directions for further work in the area are proposed.

\subsection{Theoretical Background}

\subsection{Social Innovation \& Development}

The capability to innovate and to bring innovation successfully to market will be a crucial determinant of the global competitiveness of nations over the coming decade (OECD, 2007). It is estimated that between 50-80\% of economic growth comes from innovation and new knowledge (Mulgan, 2006) and (through a feedback effect) economic activity promotes innovation activities (Galindo and Méndez, 2014). The problem, however, is that the traditional innovation paradigm places a great deal of emphasis on the science and technology (S\&T)-focussed application of the term “innovation" (Cloutier, 2003; De Muro et al., 2007; Hochgerner, 2009; Howaldt \& Schwarz, 2010; Klein \& Harrison, 2007; Vienna Declaration, 2011). This paradigm leads to policies which are heavily focused on infrastructure diffusion. Indeed, the quality of basic ICT infrastructure has seen considerable improvements year on year in developing countries (Heeks, 2010). Unfortunately, the failure of such S\&T-focussed policies has been playing a role in the uplift of social problems created by issues such as unemployment, corruption, urban overcrowding, increased conflicts and so on (SSIR, 2013). As a result, a paradigm shift is now occurring which emphasises on a "new nature of innovation", with a number of critical characteristics that differentiate it from innovation in the industrial era (Prahalad et al., 2009). Within this new paradigm of innovation, there is an emphasis on innovations that are "hidden" from the point of view of "traditional" conceptualizations and measures of innovation. Social innovation falls within this new paradigm. 
Social innovations are innovative solutions to problems in society that mobilise ideas, capabilities, resources, and social arrangements required for sustainable social transformation (Alvord et al., 2004). They present new solutions to some of society's most pressing problems such as those linked to economic development and health and education services for marginalized sections of the community (Datta, 2011). Across the world during the past decade, there has been a phenomenal surge of interest in social innovation as a way to achieve sustainable economic development (Dawson \& Daniel, 2010; Graddy-Reed \& Feldman, 2015). This interest comes in the wake of claims for a more responsive role of governments to address long-standing social problems affecting the most vulnerable populations in developing countries.

There has been a perception, justified or not, that policy makers are not paying enough attention to what innovation has to offer and on the ways it could be operationalized in order to meet basic development needs. The traditional focus in innovation policies has been on research and development (R\&D), however, increasingly, it is being shown that innovation goes far beyond industrial $R \& D$. There is a significant role of tacit knowledge, experience, and learning capabilities, particularly when considering these aspects in developing countries. Therefore, in order to promote development, there is a need to include different types of activities, actors, beneficiaries, tools, themes, objectives, rules, frameworks as well as new challenges and strategies (Bortagaray \& Ordóñez-Matamoros, 2012). The value of SI is now being taken seriously as an opportunity to shape the responses of governments, researchers, social innovators, entrepreneurs and philanthropists to new social realities, generating new solutions, connecting with citizens, and promoting reforms (Moulaert \& Mehmood, 2010; Hubert, 2011;).

It is acknowledged that the diffusion of technological infrastructure and even usage has been dramatic (Heeks, 2010); the addressing of social problems, however, requires the availability of information (ITU, 2013). 'Infrastructure availability' does not equate to 'information availability'. Software applications that are usually free to use and cost very little to develop and update have the potential to provide timely and actionable information to marginalized communities, thereby, creating opportunities for economic upliftment. However, scholars have raised concerns over the value of ICT-based SIs in 
developing economies, citing that such innovative programs often fail to adequately engage with target grassroots beneficiaries (Pick et al., 2014; Prakash, 2015). FOSS and its accompanying open source ethos is a promising platform which can be promoted to improve information availability for the economically marginalized. In the next section, the important role of FOSS as an approach for promoting human and economic development via SI is presented.

\subsection{FOSS's Benefits to Developing Countries}

There are a number of definitions of FOSS; we adopt the definition put forth by the Free Software Foundation (FSF) as it is a focal body in the FOSS movement (Stallman, 1999). According to FSF, a program is free software if the program's users have four essential freedoms; the freedom to: (1) run the program, for any purpose; (2) study how the program works, and change it - access to the source code is a precondition for this; (3) redistribute copies; and (4) distribute copies of modified versions. Software based on these four freedoms has contributed to changing paradigms within the software industry, blocking traditional firms' efforts to commoditize proprietary software packages, and threatening the industry's high profits (Pykalainen, 2007). FOSS has attracted considerable commercial interest because of its promise to cheaply and reliably address organizational needs (Agerfalk \& Fjeldstad et al., 2012; Kilamo et al., 2012; Reed et al., 2012). It is seen as a new innovation model that has spurred the developed of altogether new business models (Hippel \& Krogh, 2003).

To create value or wealth in a developing country economy, software must create business opportunities for private firms, reduce cost of IT investment in the private and/or public sectors of the economy and improve the efficiency and effectiveness of government (Weerawarana \& Weeratunga, 2004). Software constitutes the set of instructions that enable hardware devices to perform their desired functions. It represents a critical component of almost all goods and services including cars, telecommunications, consumer electronics, medical devices and so on (Stryszowski, 2009). Since software is embedded in many final goods, equipment and productive processes, a capacity to understand, manipulate and adapt software is necessary for countries to be able to successfully absorb new technologies in a variety of areas (Zavatta, 2008). Further, developing country companies wanting to participate in global 
supply chains need access to competitive software solutions. Without a relevant set of domestic capabilities to adopt, adapt and develop relevant software and applications (reflecting the mix of ICTs that are available in an economy), DCs will find it increasingly difficult to participate in the learning processes that are essential for the development of their information societies (Maldonado, 2010).

FOSS responds more rapidly to market demands and regenerates itself more quickly than any monolithic vendor of closed-source software (Yildrim \& Ansal, 2011). Hence, its potential for developing countries in particular, with the resource constraints they face, lies in reducing the cost of ICT investment and increasing its productivity (Postner et al., 2015). Weber (2003) argues that the imperative to adopt and use FOSS in such countries is motivated by a desire for independence, a drive for security and autonomy and a means to address intellectual property rights enforcement. Countries around the world have been keen to minimize their reliance on single suppliers of software, since such suppliers may not be aligned with the country's development objectives and to avoid becoming victims of opportunism which is possible in locked-in proprietary software purchases (Camara \& Fonseca, 2007). The use of FOSS means that support and maintenance can be freely contracted out to a range of competitive suppliers or managed in-house. Maintenance is furthermore replicable without incurring large costs, since modifications to the source code are also free (Reed, 2006).

A number of studies have been published in recent times which assess the benefits of FOSS for developing countries [see for e.g. UNCTAD (2012); Yildirim \& Ansal, (2011); Maldonado, (2010); De', (2009), Weerawarana \& Weeratunga, (2004); Bruggink, (2003)]. The work of De' (2009) is especially instructive for this paper; De' (2009) presented an economic impact assessment of FOSS in India. The research, based on twenty case studies of Indian organisations in a variety of sectors using FOSS, shows that adopting FOSS resulted in very tangible cost savings by presenting viable substitutes for expensive proprietary software for servers, desktop operating systems, office productivity and other complimentary software such as antivirus applications. In addition to cost savings, FOSS facilitated the ability to try out and experiment with different software for particular applications, enabled experimentation and customization and allowed free distribution and installation on multiple computers. 
DC policy makers are beginning to see the benefits of FOSS and as Postner et al. (2015) and Yildrim \& Ansal (2011) report; the innovation and technology policies of countries such as Argentina, Brazil, Venezuela, China and South Africa now have active directives for the adoption and use of FOSS for development purposes.

\subsection{Social Enterprises, User Involvement and Social Innovation}

Research on SIs has gained momentum over the last decade, spurred notably by the growing interest in social issues related to management, entrepreneurship, and public management (Cajaiba-Santana, 2014). SIs provide good examples of user involvement in the innovation process. User involvement refers to users developing or actively contributing to innovations (Hippel, 2005). For instance, women borrowers (target beneficiaries or end users) of Grameen Bank's credit delivery system share responsibility for loans granted to group members (Mair \& Marti, 2006). Similarly, in the case of the Big Issue magazine, the homeless in the UK are involved in the sales of the magazine (Hibbert et al., 2002). Thus, end users or target beneficiaries are actively engaged in the development and implementation of social innovations; in other words, co-creating value with social innovators.

Social enterprises (SEs) are able to actively engage marginalised groups (or end users) in the social innovation process because all or part of the benefit of a social innovation accrues to the marginalised group being served (Tan et al., 2005). The innovating SE also benefits as it is able to leverage the group social capital (of the marginalised group), which reduces the financial capital required for the innovation. Further, SEs compete more on the input side for resources; competition in the output side (markets) is rare given the wide scope of social innovations (Prabhu, 1999). In the absence or weak influence of market mechanisms in the social sector, the end user of a social innovation can be viewed as the final arbitrator of the success of a social innovation.

For instance, in Grameen Bank case, involvement of women borrowers in loan repayments reduces the need to pay trained staff to monitor loans. Similarly, by using the homeless as vendors, the Big Issue magazine reduces the need to appoint sales agents and setting up sales offices. In contrast, not all commercial innovations provide benefits or are attractive to all users as it is the innovator who is the major beneficiary 
of innovation-based profits (Hippel, 2005; Hippel, 1986). Highly specialised manufacturing equipment might only be valuable to a given manufacturing company and the same argument is valid for highly-customised products.

In contrast to commercial innovation where success is judged by successful commercialisation in the market (Drucker, 1985), the success of a SI can be judged on its ability to further the social mission of a social enterprise (SE) (McDonald, 2007). If the mission of a SE such as the Grameen Bank is to provide economic opportunities to rural women then its innovation - micro credit - would be judged on its ability to serve those women.

In general, the market selection mechanisms for commercial innovations are fairly intense as innovation is one way that commercial enterprises gain competitive advantage (Wolfe, 1994). In the social sector, these mechanisms are less intense because they tend to be less powerful and act over longer periods of time (Austin et al., 2006). Besides, in both non-profit and for-profit SEs, the social entrepreneur defines a social entrepreneurial opportunity motivated by their realisation of a market failure - an area where markets do not do a good job of valuing social innovation, public goods and benefits for people who cannot afford to pay (Dees, 1998).

To sum up, economic marginalization is a difficult problem to address, and it has been shown that top-down developmental approaches based on providing access to ICT infrastructure have failed to deliver intended results (Borzaga \& Bodini, 2014). To address the problems of marginalized communities which are exacerbated by inequitable access to information, social innovation, social enterprises and software developed and distributed under the open source ethos can be brought together in a framework based on and driven by active user engagement and value co-creation. 


\subsection{Methodology}

\subsection{Choice of Location, Research Organization and Embedded Case Study}

The aim in this research is to undertake an investigation of the development methodology of FOSS-based social innovations conceived, coded and launched by a social enterprise in a developing country. The focal country, participating organization and the specific case of FOSS-based SI will provide the means for glimpsing into processual dynamics and unearthing hidden mechanisms.

India is associated with high levels of social entrepreneurial activity and several case studies of social innovations introduced by Indian social enterprises have appeared in the literature (Sen, 2007; Mair \& Marti, 2006; Nicholls \& Cho, 2006). Research points to a number of social, cultural and institutional factors that have spurred development of entrepreneurial solutions to social problems. For instance, rural poverty was a significant socio-economic issue and over 650 million individuals or $70 \%$ of the population living in rural India are estimated to live below the poverty line (Poon, 2011). In the past decade, rapid growth has widened income disparities while exacerbating environmental problems in emerging economies in general (Hall, Matos and Martin, 2014). In the case of India, socio-economic development patterns suggest that development in the Southern regions is far more symmetrical than in Central and Northern Regions (Ohlan, 2013). These challenges have spurred development initiatives by the Indian government for more inclusive innovation as chalked out in its current five year plan.

To bridge the digital divide for the rural poor, a number of ICT4D initiatives were initiated in several states of India by local governments, large corporations and NGOs (Prakash \& De, 2007; Madon, 2005). The development impact of these early attempts has been widely contested. However, ICT and other professionals with entrepreneurial backgrounds engaged with rural communities in these development projects laid the ground for a whole new type of implementation approach. It is believed that such entrepreneurial professionals' exploration of issues facilitated the initiation and development of sustainable ICT based social innovations. The study of Indian social enterprises is, therefore, useful for examining social innovation processes that convert opportunities and needs of marginalised communities into social innovations. 
The empirical setting for the study was a technology-based, not-for-profit, social enterprise in India - Mahiti Infotech Pvt. Ltd (referred to as Mahiti henceforth). Mahiti was founded in Bangalore in 2002 by an entrepreneurial team consisting of IT and other development professionals with prior field experience in development projects in South India. Presently, it employs over fifty technocrats and sociologists committed to support social change through novel applications of technology. Over a decade, Mahiti has supported organisations in the development sector by training and developing ICTbased solutions for grassroots initiatives. Its clients range from farmer producer cooperatives in India and Africa to large social purpose organisations in India and overseas including Amnesty India, Ashoka Foundation and Oxfam India. Mahiti's product offerings include multilingual websites to management information systems developed through the strategic use of FOSS. The target beneficiaries of these products are often disadvantaged groups or organisations supporting communities at grass root levels such as the visually impaired.

During the research period (2009-2015) Mahiti was involved in a number of ICT-based social change initiatives. A majority of these projects were commercially viable; however, one particular project - OurCrop - in terms of scale, scope and impact stood out. OurCrop is an FOSS software system developed by Mahiti for institutions engaged in the agriculture sector such as Farmer Producer Cooperatives. This low cost system enabled farmer cooperatives, individual farmers, government agencies, research institutions and universities to track, monitor and assess the effectiveness of farming activities such as project management, crop procurement, food processing, inventory management, and marketing operations in multiple locations.

OurCrop was first implemented in 2012 in a farmers' cooperative in the Indian state of Maharashtra serving 5000 cotton farmers. Its interface was developed in Marathi, the spoken language of the local farming community. Later, OurCrop was customised and successfully implemented in two districts of Andhra Pradesh in the Telegu language for 1000 Farmer Cooperatives engaged in groundnut, soya and pulse production with an estimated outreach of 50,000 farmers in the region. 
OurCrop was developed as a lightweight FOSS application that could operate without an expensive hosting infrastructure, customised for each Farmer Cooperative aligned their business models. The field officers of the Cooperatives usually used a tablet device to capture data offline in the field and this data was then synched with the main system database. This data could then be used for diagnostic study and feasibility analysis of agricultural processes and other operations of the Cooperatives including training and monitoring.

OurCrop has also been successfully internationalized. For instance, in East Africa, OurCrop has been developed in Swahilli. In Tanzania, OurCrop was customised for a Microfinance institution supporting the development of 12,000 coffee growers and in Kenya for over 80 farmer groups producing coffee and fruits. In terms of total outreach, it is estimated that by 2015 , over 100,000 farmers would have been supported by this system. In essence, OurCrop is an exemplar social innovation demonstrating the relevance of FOSS-based solutions for farmer cooperatives and similar institutions in developing countries.

\subsection{Research Design \& Assumptions}

To address the research's purpose, an approach was needed that allowed for the emergence of key patterns through an immersion in the research subjects' world i.e. organizational actors engaged in the social innovation. From the standpoint of research design, it is argued that the above purpose's implications would be best met using an interpretive research strategy using qualitative data and inductive methods of analysis (Burrell \& Morgan, 1979; Blaikie, 1993; Strauss \& Corbin, 1990; Denzin \& Lincoln, 2000). Allied to the notion of induction, is the idea that contributions to theory are made posterior; in other words, theory development is the end point in this research. The interpretive perspective helps us understand the complex phenomena under study by drawing on the participants' interpretations of their context (Klein \& Myers, 1999).

This research relied on an embedded case study design; as the driving principle was to investigate "a contemporary phenomenon in depth and with its real-life context" (Yin, 2009:18). Following Stake's (1995: 1) vision of entering "the scene with sincere interest in learning and putting aside many presumptions while we learn", close discussions were held with various members in the Mahiti organization for identifying 
novel initiatives that were regarded as significant in terms of their potential or actual social impact. It was on this basis that OurCrop was chosen for analysis out of a number of other possible cases.

The limitation of studying a single case study was counterbalanced by the much deeper insight gained of novel initiatives by Mahiti and how these initiatives could contribute towards the development of FOSS based SIs. To ensure validity and reliability, there was constant clarity in the achievement of the research's aim, a focus on the extent of the research where the case study was treated like a "bounded system" (Creswell, 2007). Extensive qualitative data on Mahiti generally and OurCrop particularly was collected to understand the social innovation process.

\subsection{Data Collection}

A number of data sources are used for analysis: interviews with Mahiti staff members, field notes prepared during a site visit and archival data - such as internal documents, annual reports, websites, blogs, screen shots and news articles in order to triangulate the data. The first round of interviews was conducted in 2010 and a second round in 2015. Each interview lasted about an hour. The second round of interviews complemented the first through follow-up and clarification questions. Multiple interviews were conducted with key stakeholders such as a co-founder and project manager. As a result, data from 9 semi-structured interviews became available (see Table 1). These audio recorded interviews were transcribed, and accounts helped to capture the experiences, motivations and interpretations of the individuals involved. In addition, extensive field notes prepared by the first author during a site visit also aided in the analysis. Such notes contained, besides factual information, interpretations of the observed phenomena.

\subsection{Data Analysis}

For data analysis, the recommendations of Klein \& Myers, (1999) for interpretive case study analysis alongside those of Eisenhardt, (1989) were adopted. The data analysis process comprised of three steps. First, the interview data, field observations and secondary data was organized to build an event history database (Van de Ven \& Poole, 1990). This helped in the development of a coherent narrative around the FOSS-based 
social innovation process used by Mahiti. This narrative was cross-checked by key organizational members.

The second step was to identify themes or codes from the case study data. This involved several iterations between the case study data and insights from previous literature in order to identify meaningful conceptual categories (Eisenhardt, 1989). In this phase, memos helped in the recording of thoughts about the case and their relation to the relevant literature (Miles \& Huberman, 1994). Existing theoretical constructs in the area of social innovation and ICT for development were relied upon. This led to the development of themes that reflected three broad areas associated with FOSS-based social innovation. The third step involved 'enfolding' the research findings with further insights from the social entrepreneurship and innovation literature. This helped in the development and contextualization of findings theoretically (Eisenhardt, 1989).

\subsection{Research Results}

In this section, three themes are presented which were distilled through the analysis of case data. Considering the aim and design of this research (articulated in the previous section), the explanations in the sub-sections below on the case SE's social innovation process, its working methodology and the usefulness of its tools (FOSS) help in appropriately unpacking the causal linkages and mechanisms that address important issues of trust, sharing, participation and engagement. The purpose has been to present the most significant findings in a logical manner that would allow for the derivation of a number of research propositions.

\subsection{FOSS: A Strategic Choice for Social Innovation}

Researchers have argued that FOSS technologies offer emerging markets like India with key benefits like economic savings (De, 2009; Yildirim \& Ansal, 2011; Maldonado, 2010; Weerawarana \& Weeratunga, 2004; Bruggink, 2003). Mahiti's journey to an FOSS-based systems design and development social enterprise was not straight forward. Serendipitious events led the organisation's management to recognise that FOSS tools were best suited to develop low cost ICT solutions for clients. For Mahiti, a first introduction to FOSS-based systems design and development came in 2005 when it conducted an ICT training workshop in collaboration with a UK firm: 
"In 2005, we collaborated with TECK, a UK firm for conducting an IT training event on open source software in Bangalore. The event attracted people from 42 countries and lasted eight days. This event provided us with a potential list of clients and future partnerships"...[M4]

The event's success and analysis of participant feedback made the founders recognise the IT budget constraints of potential clients. This led them to strategically focus on building further FOSS capabilities to carve a niche:

"We believe that technology can be used for social change. For example, suppose an NGO has a Rs. 80,000/- grant (approx. £10,000). Paying for licensed software like Microsoft would cost up to Rs. 80,000/- in annual license fees itself. However, if open source software is used, this may be done in Rs. 30,000/-. The savings made in this way can be used for implementation or training needs of the NGO's staff"...[M1]

Mahiti's management, in line with the above belief, developed the internal ethos that FOSS applications had the potential to positively contribute towards social change:

"Mahiti believes that Web-based Technology Solutions and Web Tools like YouTube can be used by social sector organisations to reach out to the masses and create social awareness" (M1)

Free and open source software proponents share source code, and a core belief of the open source ideology (Lichtenthaler, 2011); Mahiti has internalized this principle, making it a part of its mission:

"Mahiti shares the source code with its clients which helps them to manage, maintain and change the content without the intervention of any technically qualified staff or system administrator....We don't have a marketing budget, queries come through our website and work"...[M4]

Mahiti, being a social enterprise, also believes in the completely free distribution of its products, its business model is based on systems design, training, implementation and ongoing customization support to clients:

\footnotetext{
"We have developed a collection of FOSS tools for running non-profits organisations called NGO-In-A-Box. This tool box can be freely downloaded from our website along with the user manuals. We are also developing another FOSS-based management information systems called 'OurBank' that is specifically designed for micro-finance institutions (MFIs) and self-help groups. We plan to distribute it freely." (M2)
} 
In order to augment its internal FOSS-based systems design and development capabilities, Mahiti actively promotes the development of open-source communities, which in turn lead to opportunities beyond software development:

\footnotetext{
"We have started using community networks of University students to generate more and more software code. We provide certification to engineering students from Universities in Bangalore through summer internships. Some of these students are now involved in our community network in which Mahiti is a pioneer in Bangalore. We now have a community of 42 to 52 people mostly students who are involved in open- software code generation." (M1)
}

Finally, in true open-source spirit, despite being a for-profit social enterprise, Mahiti as a principle does not charge for an annual license for the software it supplies:

\footnotetext{
"We believe that technology can be used for social change. For example, suppose an NGO has a Rs. 80,000/- grant (about pounds 10,000). Paying for licensed software like Microsoft would cost up to Rs. 80,000/- in annual license fees itself. However, if open source software is used, this may be done in Rs. 30,000/-. The savings made in this way can be used for implementation or training needs of the NGO's staff." (M1)
}

Mahiti's management built internal capability in FOSS-based systems design and development, which in turn added value to clients through savings in their IT budgets, and empowered them to customize the developed solution on their own once the system was developed. Such a strategic approach generated goodwill and further opportunities without entailing marketing costs.

Mahiti's atypical business model reflects the principles of open-source ideology. Evidence from the case suggests that the practice of open sourcing enhances the affordability and accessibility of ICT services for social sector organisations. In other words, Mahiti is a for-profit, social entrepreneurial venture that has developed a sustainable solution (specifically, FOSS-based ICT services) to meet the unique ICT needs of the social sector.

\subsection{Deep Immersion in Marginalised Communities}

It has been highlighted earlier that ICT4D projects in India failed to transform the lives of their intended beneficiaries as they were unable to adequately identify and solve the sort of problems marginalised communities face. For instance, the Bhoomi 
project of computerisation of land records in Karnataka did not consider that the majority of rural farmers were small and landless (Prakash \& De, 2007). Similar concerns were echoed in research by Prakash, (2015) into e-government initiatives for health and rural nutrition and Pick et al.'s (2014) study into rural telecentres in India. Since, the current thinking on ICT4D vr.2 advocates greater beneficiary engagement (Heeks, 2012), it was conjectured that close interaction with marginalised communities would be important in identifying the 'nuts and bolts' of their problems and the inadequacy of existing solutions, thereby, triggering ideas for the development of new social innovations. By creating and capturing value from external knowledge networks such as marginalised communities and universities, social enterprises can adopt an open approach to innovation (Denicolai et al., 2014).

Evidence from the research indicates that organisational actors in Mahiti were able to identify problems or information needs of beneficiaries through a deep immersive process with rural communities. Such a level of immersion requires the overcomming of a number of barriers of which, langugage is a significant one:

"......I realised some of the challenges in development projects. For example, the target beneficiaries were rural folk who spoke regional languages "...[M3]

To address the language issue, Mahiti's management strategically developed multilingual capabilities:

“....Because we take local people or people who can speak regional languages who go and train our clients we have received amazing feedback"...[M1]

In the case of OurCrop, Mahiti's multilingual capabilities facilitated interaction with rural communities. In 2012, Mahiti was involved with a number of social purpose organisations for an irrigation project sponsored by the Indian conglomerate, Tata. During the course of the fieldwork, while interacting with cotton farmers' producer cooperatives, the idea for OurCrop developed, almost as an epiphany:

“....I am familiar with North Indian languages.... as long as language barrier is not there, I found the farmers quite open....... The idea for OurCrop came to my mind probably in 2012 when I was in a village for a self-help groups development in an innovative irrigration programme for our other product OurBank. This was in the 
Vidarbha region in Eastern Maharashtra that is the cotton belt of India and nearby was the largest cotton auction point of India...Actually, after the meeting, I told them I find this gap here and do you think you need a solution? "... [M9]

Multilingual capabilities were useful while customising OurCrop for other users as reflected in this quote:

“...For South India, OurCrop's interface was in Telegu in Maharashtra it was in Marathi and in East Africa it is in Swahilli"....[M9]

Information gathered by spending extended lengths of time at Farmer Producers' Cooperatives helped in developing contextualised knowledge on the unique agricultural practices associated with cotton, soya, pulses and groundnut production:

"...In the beginning, I worked with these farmer groups...So, my basic approach is that if I have to work with a farmer I have to be in the field-...Initially, the system was conceived for cotton farmer groups but in a nutshell when OurCrop was implemented it was for groundnut, soya and pulses growers"...[M8]

To gain further insights, the two social data and analysis leads at Mahiti visited agricultural scientists and staff at agricultural universities. The learning journey helped in developing specialised knowledge on farmer behaviour, the nuances of crop production processes and long rooted agricultural practices:

“... I went to the technical people...the Department of Agriculture and Cooperation with 8 Directorates in India...I was in regular interaction with the Directors itself. I then went to 3 or 4 Agricultural Universities...to Pune, Karnataka and..Varanasi. There I took the views of agricultural scientists and found out what was the crucial data that they required for research like data on irrigation or on fertilisers... This would be useful when designing a system for research organisations... For support organisations I spoke to farmers and field officers. That is how I developed my knowledge.... "...[M8]

"....it is a very simple system-when they grow how they harvest? I had to find out about 7 stages of farming-there are several stages in farming/cultivation process-from deweeding to harvest to marketing stages. So, I need to know all these stages of cultivation and then I need to find out if I have to link with the system then what is the data required at each stage? I need exact details to find out how the cost of cultivation can be reduced which is the most crucial part for the supporting organisation and in marketing how marketing costs are reduced. If these costs are reduced then only the farmers will benefit. These are the basic things I have to keep in mind"...[M9]

Deep interaction with beneficiaries helped in the evolution of OurCrop's software specifications. OurCrop was first presented as a rudimentary database, its features and functionality significantly changed as Mahiti gained deeper insight into the real 
requirements of target beneficiaries. These findings resonate with Díaz \& Urquhart, (2009) who suggested that successful ICT intervention within developing countries requires a careful unpacking of context, taking into account perceptions of ICTmediated information and linked mechanisms.

\subsection{From User Requirements to Customization \& Adoption}

As highlighted in the previous section, Mahiti's software development process commences with the identification and unpacking of beneficiary problems through deep immersion in their life worlds. Mahiti social scientists who develop such deep understanding of the socio-cultural context within which beneficiary problem(s) exist need to conceptualize effective software solutions and then translate such solutions' requirements to software developers.

In the case of Mahiti, its management adopted the open source ideology which espouses open sharing of source code with clients and enhancing community participation in software development (Bughin et al., 2008; West \& Lakhani, 2008). This is an iterative process and such beneficiary engagement in developing ICT solutions is espoused in the ICT4D vr.2 discourse (Heeks, 2012). Mahiti's founders explains the FOSS approach:

"Our Philosophy is to support FOSS. Mahiti believes in sharing knowledge and that intellectual property is better to share with clients. ”... [M3]

"...We share the source code.....It is good at evolving technology that can be shared across generations and by sharing we can only help in sustaining new knowledge."...[M2]

Scholars argue that open-source presents a paradigm shift in software development as in it users program to solve theirs as well as shared technical problems, and freely reveal their innovations (Hippel, \& Krogh, 2003). In contrast, proprietary software such as Microsoft's Windows can be used only on purchasing an annual license. This implies that proponents of open-source aim to enhance the accessibility and affordability of software for a wider audience which emphasises the social nature of such innovation. However, a software coding platform is only effective if emergent solutions are well aligned with beneficiary problems; this alignment not only requires, a deep immersion in the beneficiaries' life-worlds but also an effective translation of 
the conceptualised software's specifications to developers and setting up testing protocols:

".....We translated the requirements to the coders. Actually, that is my principal job. To understand the entire process and analyse its flows. I then put it in a simpler form to the user to check whether I am right or wrong? I get their inputs and with all those things I come back to the coders in-house and then they translate this to the technical language and develop the product"... [M9]

"My skills lie in technology consultation, design and in localisation which is translating IT information in 5 to 6 regional languages...we use agile approaches in software development" ...[M1]

The software methodology deployed by Mahiti is a variant of the popular agile software development approach. Using this approach, the software design for OurCrop emerged organically over time; the initial system conceived was customised numerous times to incorporate unarticulated or hidden user requirements and rapidly evolving field conditions. The following quote elaborates on the first implementation of OurCrop in 2012 at a cotton farmers' producer cooperative in Maharashtra, India:

"So, there was a gap in the available data as far as the farmers' cooperative... So, there it came to my mind that we can provide a solution to these supporting organisations where they can maintain all these records in a very simple form of MIS...simple, there are two aspects of one MIS-one is a profile database and the other is an operational or application database. Through these two database we have a transaction mechanism and then we find out what are the results so that we can pull out the reports. This was the simplest form of OurCrop" [M9]

By gaining a deeper understanding of user requirements, the initial OurCrop implementation evolved considerably:

"If I have to know the cost of cultivation then I have to know all the parameters of cultivation..For coffee there are no parameter restrictions whereas for groundnut there are three... and then I have to find out which of these is most crucial. Accordingly, I have to design the system... When I am designing for coffee or groundnut or soya bean, I have to put it in different way. That is how I would analyse and do it" [M8]

Further development was made through a process of ongoing customization triggered by the beneficiary community:

"....they made suggestions relating to the field conditions-one suggestion was they had a system some sort of a buy back policy...the support organisations gave the loan to the farmer-sort of micro-finance-and the loan was adjusted in a phased manner. They 
suggested that there was no provision for this in the original system. Most of the farmers take a loan to buy seeds and fertilisers, then they produce and then they come back and sell the produce.....In the normal instance farmer will invest his capital in growing crops but when the farmers are very poor the supporting organisations provide them with money and with that money they cultivate crops they produce and they sell it back to the cooperative"...[M8]

"Another suggestion was that in some cases like pulses or soya for example in the system there is a fixed price or rate based on some parameters say percentage humidity but sometimes in addition they use other quality parameters for each crop that changes with market conditions then we need to incorporate these different pricing according to some quality parameters. This is what you can call field conditions adjustments to price paid"...[M9]

When asked to elaborate on challenges in user adoption, a Social Data and Analysis Lead explained:

"...when you are working with farmers or field officers who are not very computer literate...it is a bit difficult for them to understand the connection. Each process is interlinked, like if I procure then it gets stored in an inventory and then it goes to processing. So, there is a continuous process and when it is a paper process or it is manually done, half of the things are in the memory and half of the things are noted down somewhere else. That is how they are accustomed. So, it is slightly challenging to make them understand how they to adopt to the system. But once it was done, it was very easy for them and then they came back with some suggestions about their operations"...[M8]

The scaling period in a social innovation depicts a period of accelerated growth (Pol \& Ville, 2009) wherein the original concept is replicated in different contexts and achieves sustainability. To ensure replication of OurCrop, cost savings to farmer cooperatives was seen as a significant attractor point. The benefits accrued to cooperatives from effective management facilitated by OurCrop were tangible and their impact promoted adoption of the software:

\footnotetext{
"When we started, the cooperatives were losing money...about $3 \%$ margin as there was no proper record keeping about procurement. All the data was manual and also the waste was not being accounted for... When the system was implemented, records could be maintained accurately there was much transparency. They found at the end of a year that they could make up the los..." [M9]
}

ICT applications can empower marginalised populations like the rural poor as "access to information is one of the arrangements that society makes (others beings education, healthcare) which influences the individual's substantive freedom to live better" (Sen, 
1999, pg. 39). OurCrop gave farming communities access to relevant, timely and actionable information that made a useful and measurable impact on their economic well-being. Elaborating on the benefits of OurCrop to rural farmers in India, Mahiti stakeholders highlighted the following:

"The farmers were very happy because there was so much confusion with procurement and data entry. [M5]

"Because now there was much transparency-when the purchase is made from the farmer the SMS goes to him showing the price purchased today and he will get the price even if the price goes down while procuring-so the system shows the promised rate only even if the rate goes down. So it was a big relief for the farmers to get transparency on the procurement price". [M8, M9]

Mahiti works with its own version of an FOSS-based software development methodology based on the principles of agile development - one which aims to deliver software-based technical solutions to age old beneficiary problems rooted in custom, social hierarchy and micro-institutions, all of which are resistant to change. To overcome such resistance requires the sort of deep immersive approach that Mahiti has been perfecting over many years. Mahiti's skill and expertise in aligning the 'social' with the 'technical' and vice-versa have aided in the wide-scale adoption of the OurCrop system.

OurCrop, which started as a self-funded initiative of Mahiti in 2012 implemented at a single farmer cooperative, has now scaled through the help of partners to across India and beyond to Kenya and Brazil. This has only occurred because the OurCrop system demonstrated tangible results to end-users, made possible by Mahiti's unique immersive approach to systems design and implementation, backed by infinitely customizable and scalable FOSS-based software tools.

\subsection{Discussion}

Our results contribute to the understanding on FOSS-based social innovations in developing countries. Case findings support the current thinking on ICT4D vr.2 elaborated earlier in this paper that suggests that beneficiary engagement to co-develop solutions is a more effective approach to reaching those marginalized by digitization. As Borzaga and Bodini (2014) point out, successful ICT intervention requires a deep understanding of context such as perceptions of ICT-mediated information and the 
possible mechanisms it activates, socio-cultural barriers and issues surrounding literacy and language. It is argued, that due to the extreme nature of socio-economic problems and the degraded nature of the working environment in developing countries, de-coding users' context of ICT use is far more complicated when compared to developed economies. Standard approaches for capturing user requirements, systems analysis and design and building software specifications which often yield working guidelines for software developers often fail to yield valuable outputs in a developing country context. Basic FOSS development requirements and processes, reliant on ICT competency, English language proficiency, the availability of broadband and computing hardware, become long drawn out and cripplingly complicated. Hence, SEs like Mahiti, have departed from traditional models of FOSS-based software development, and instead deployed their own more contextually relevant approaches.

A number of theoretical propositions can be derived from the analysis presented in the previous sections. First, it is proposed that for ICT/FOSS-based social innovations to be successfully adopted and used in a populous and culturally diverse country like India, they must be championed through the vision and energy of social entrepreneurs. Mahiti - an SE - recognised a social entrepreneurial opportunity, that is, the existence of accessibility issues for deployment of ICT for development projects in rural India. They also conjectured a solution, that is, to start a social enterprise with the aim of providing low-cost FOSS-based ICT solutions to community organizations comprising mostly of unskilled or semi-skilled rural folk. In this manner, Mahiti's contribution to the social upliftment of the marginalized has been significant in comparison to infrastructure heavy donor or government (or combination thereof) funded ICT4D projects.

Second, it proposed that target beneficiaries need to be actively engaged in the SI process. During the development of OurCrop user inputs extensively informed the software design and development process. Inputs from the farming community (the target beneficiaries) were gradually drawn out during an extended engagement, where Mahiti social scientists adopted the stance or disposition of 'curious learners'. It is proposed that for the purposes of understanding the ICT requirements of marginalised user communities, FOSS-literate social scientists (and not software developers or systems analysts) unpack the intricacies of beneficiary life-worlds, refraining from 
acting as experts providing ready-made solutions. In large part, the success of OurCrop was due to an emphatic yet professional customer-centric approach to software development and design that formed a crucial part of Mahiti's working ethos. We find that a growing number of social enterprises in India have engaged marginalised communities, in the manner being proposed, for software development and implementation (Madon and Sharanappa, 2013; Heeks and Arun, 2010).

Third, it is proposed that the ongoing use of a SI would be dependent on target beneficiary empowerment, allowing such beneficiaries to help themselves customize and build upon provided ICT-based SIs. Here, Mahiti's ethos based on open-source principles (not just software tools) played an important role. A central practice in opensource development is the collaborative process of distributed co-creation with the enduser. In this process, developers share the source code with the end-user, enabling them to make modifications. Not only did Mahiti hand over source code, they also offered to train target beneficiaries in software customization. Thus, training beneficiaries to customize source code can be viewed as a powerful means of end-user empowerment which encourages their greater participation in the SI process. It is proposed that in developing countries, the sharing of source code, although a useful first step, would be no guarantee towards the adoption and long term use of an FOSS-based SI. The implementing SE, in order to build trust and to offer true empowerment, must also equip the beneficiaries achieve self-reliance through training and other capacity building activities.

Fourth, it is proposed that the SI implementing SE carefully consider extant cultural and social intricacies, and as to how these may be (both positively and negatively) impacted with the arrival and adoption of the new SI. Seemingly innocuous issues such as levels of literacy and language proficiency can pose at times insurmountable challenges during the development and deployment phases. Pre-existing power structures and micro institutions that govern social status and hierarchy within families and communities also need to be carefully internalised. India's unique socio-cultural milieu in which religion, ethnicity, shared values and the caste system play extremely significant roles, for outsiders, can be extremely difficult to untangle and decode. Thus, SEs like Mahiti, understand the significance of the ethnographic process of becoming an "insider" while navigating India's rich rural socio-cultural landscape, fishing for 
information and getting buy-in. Through regional language capability, OurCrop contributed to ease of training, use and therefore adoptability; delivering appropriate and meaningful information to target beneficiaries. In addition, it was also the trust and respect that Mahiti built and demonstrated to a whole range of power brokers and stakeholders within the OurCrop usage community that led to successful implementation and ongoing use.

Fifth, it is proposed that the potential for FOSS-based SIs (configured and aligned to domestic markets) to internationalise needs to be established through collaboration and experimentation with SE partners in other developing countries. Mahiti developed OurCrop in India but later successfully implemented the system in agricultural cooperatives in Kenya and Brazil. Like any other commercial partnership, the presence of trust and mutuality was a necessary prerequisite; in addition, other relational parameters driven by the principles of FOSS, such as sharing of source code, designs and development experiences, were also important. Other developing countries, such as those in Africa, although do share some common features with India (infrastructure degradation, economic inequality, lack of transparency and so on), to mistake them as being socio-culturally similar would be irresponsible. The adoption and ongoing use of SIs is dependent on whether they are well aligned with and complement existing social structures. Developing such SIs, as articulated previously, requires the implementing SE to adopt an immersive process of becoming an "insider" within the beneficiary community and learning about socio-culturally embedded practices and rules. Hence, a key to successful internationalisation for FOSS-based SIs would be to collaborate with partners who share the above ethos and have the capability and capacity to immerse themselves in the life-worlds of beneficiary communities with a view to developing knowledge on what is actually needed, what aspects of an SI might work and under what conditions failure would most likely occur.

Finally, findings from this research are in line with and inform new literature on product and service innovation in Base of the Pyramid (BOP) markets. It is being increasingly suggested that BOP markets provide innovation opportunities to corporations that while being profitable also contribute to social and environmental improvement within poor communities (Silvestre and Silva Neto, 2014; Zamani-Miandashti et al.2014; Hall et al., 2014; Foster and Heeks, 2013). BOP innovations introduced in India through 
Corporate Social Responsibility (CSR) initiatives for instance have resulted in radical and reengineered product innovations (Ramani \& Mukherjee, 2014). This occurred for those CSR efforts which were associated with a strong social mission; as these were able to attract wider community support. Outside the realm of CSR, corporations in India, aligning themselves effectively with the country's socio-cultural milieu, have adopted the 'frugal innovation' approach (Bound \& Thornton, 2012). Frugal innovation works on the principles of bricolage, responding to limitations in resources, and turning constraints into advantages. Through minimising the use of resources in development, production and delivery, or by leveraging them in new ways, frugal innovation results in lower-cost products and services for end-users. Mahiti's work is based precisely on the frugal innovation approach; they are a social enterprise, deploying emerging ICT applications based on FOSS and work as active partners with local communities to promote development (Sunday, et al., 2014). Though there are important points of departure with the state, multi-lateral and bilateral funding agencies and private corporations: these would be differences in founder/management motivations and organizational ethos and business models. It is proposed, that the SE model as the lead social innovator, innovating using the principles of FOSS is the ideal way forward for delivering pro-poor development.

\subsection{Conclusion}

Since the 1990s, India has emerged as a major global player in software development. The ICT sector in India has contributed to economic development through the export of ICT services and the creation of employment for skilled workers. However, the benefits of ICT export revenues have not accrued to the marginalised in Indian society, nor have such exports made any significant impact on quality of life indicators for the very poor. Researchers suggest that developing countries like India use ICT tools such as mobile phone technology and the internet to facilitate access of information to marginalised populations for the purposes of social upliftment (Avgerou, 2008; Kenny, 2000). With the failure of top-down infrastructure heavy projects, such as the rural telecentres movement in India, there has been a distinct absence of ideas, approaches and models that are workable and viable and have demonstrated promising results. In this paper, just such a model has been explained, one that has been making a demonstrable impact on the lives of marginalised rural farming 
communities, based on the triad of social enterprise, social innovation, and free and open source software - the case of Mahiti Info Tech's FOSS-based OurCrop social innovation for rural farming communities.

Mahiti has successfully deployed a business model and a software design and development methodology that has resulted in the implementation of a number of social innovations, of which OurCrop has had the most significant impact. A number of propositions have thus been derived from the OurCrop case; first, ICT/FOSS-based social innovations can indeed be adopted and used in populous and culturally diverse developing countries if they are championed through the vision and energy of local social entrepreneurs. Second, target beneficiaries need to be actively engaged in the SI process. During the development of OurCrop user inputs extensively informed the software design and development process. Such inputs were drawn out during an extended engagement with target users (the farming community). Mahiti social scientists (and not software developers or systems analysts) took the stance of curious students wanting to learn, rather than experts providing ready-made solutions. Third, target beneficiaries need to be empowered to help themselves customize and build upon ICT-based SIs. Here Mahiti's strategic ethos based on open-source principles played an important role. Not only did Mahiti hand over source code, they also offered to train target beneficiaries in software customization. This can be viewed as a powerful means of empowering end-users. Fourth, there is an important requirement to carefully consider levels of literacy and language proficiency when designing solutions. Through regional language capability, OurCrop has contributed to ease of training, use and therefore adoptability; thereby, delivering appropriate and meaningful information to target beneficiaries. Fourth, the implementing SE must display sensitive awareness about and forecast likely impact of pre-existing power structures and micro institutions that govern social status and hierarchy. The marginalised in developing countries turn to religion, ethnicity and develop shared values which, for outsiders, can be extremely difficult to untangle and decode. Their impact on overall success, it is argued, is far greater than the overcoming of technical challenges. Fifth, for internationalising successful FOSS-based SIs, the lead SE needs to establish collaborative relationships with likeminded SE partners in other developing countries who have the capability and capacity to immerse themselves in the life-worlds of beneficiary communities.

Through the presentation of the above insights, the present study has furthered our 
understanding around the social innovation process deployed by social enterprises in a developing country context. The study's results can provide useful avenues for future research on FOSS-based social innovation championed by social enterprises. For instance, a comparative analysis of the social innovation phenomenon from the perspective of different cultures, political systems or economic environments; development of conceptual models highlighting systems design and development approaches based on open-source principles that work to deliver meaningful results to the most marginalized in society; and, an investigation into the interplay between the business model, founders' vision and operational strategy of social enterprises championing software-based social innovations. 


\section{References}

Agerfalk, P. J., and Fitzgerald, B. 2008. Outsourcing to an unknown workforce: Exploring opensourcing as a global sourcing strategy. MIS Quarterly, 32(2), pp. 385-409.

Alkire, S., Roche, J. M., Seth, S., and Sumner, A. 2015. Identifying the Poorest People and Groups: Strategies Using the Global Multidimensional Poverty Index. Journal of International Development, Special Issue: Global Development beyond 2015: Reflections on the post 2015 debate, 27(3), pp. 362-387.

Alvord, H. S., Brown, D. L., Christine, W. L. 2004. Social entrepreneurship and societal transformation: An exploratory study. Journal of Applied Behavioural Science, 40 (3), pp. 260-282.

Austin, J., Stevenson, H., and Wei-Skillern, J. 2006. Social and Commercial entrepreneurship: Same, Different, or Both? Entrepreneurship: Theory \& Practice, 30(1), pp. 1-22.

Avgerou, C. 2008. Information systems in developing countries: a critical research review. Journal of Information Technology, 23, pp. 133-146.

Blaikie, N. 1993. Approaches to Social enquiry. Polity Press, Cambridge, pp. 58-62.

Bortagaray, I., and Ordóñez-Matamoros, G. 2012. Introduction to the Special Issue of the Review of Policy Research: Innovation, Innovation Policy, and Social Inclusion in Developing Countries. Review of Policy Research, 29(6).

Bound, K., and Thornton, I. 2012. Our Frugal Future: Lessons from India's innovation system. NESTA, UK. Available at: http://www.nesta.org.uk/sites/default/files/our frugal future.pdf.

Borzaga, C., and Bodini. R. 2014. What to Make of Social Innovation? Towards a Framework for Policy Development. Social Policy and Society, 13(3), pp 411-421.

Bruggink, M. 2003. Open source software: take it or leave it. The Status of Open Source Software in Africa, International Institute for Communication and Development, Research Brief No UICT01.

Bughin, J.R., Chui, M., and Johnson, B. 2008. The next step in open innovation, McKinsey Quarterly, 4, pp. 112-122.

Burrell, G., Morgan, G. 1979. Sociological paradigms and organizational analysis: Elements of the sociology of corporate life. Heinemann, London.

Cajaiba-Santana, G. 2014. Social innovation: Moving the field forward. A conceptual framework. Technological Forecasting and Social Change, 82(Feb), pp. 42-51.

Camara, G., and Fonseca, F. 2007. Information policies and open source software in developing countries. Journal of the American Society for Information Science and Technology, 58 (1), pp. 121-132.

Center for Global Development. 2015. MDG Progress Index: Gauging Country-Level Achievements. Available at: http://www.cgdev.org/page/mdg-progress-index-gaugingcountry-level-achievements, [Accessed $20^{\text {th }}$ August, 2015]. 
Chaminade, C., Lundvall, B.A., Vang-Lauridsen, J., and Joseph, K.J. 2009. Innovation policies for development: towards a systemic experimentation based approach, 7th Globelics Conference, October 6-8, Dakar, Senegal.

Cloutier, J., 2003. Qu'est-ce que l'innovation sociale? Collection Études théoriques No ET0314, CRISES, Montreal.

Cornell University, INSEAD, and WIPO, 2013. The Global Innovation Index 2013: The

Local Dynamics of Innovation, Geneva, Ithaca, and Fontainebleau.

Creswell, J. W. 2007. Qualitative Enquiry and Research Design: Choosing Among Five Approaches. Sage Publications, Thousand Oaks, CA.

Datta, P.B, 2011. Exploring the evolution of a social innovation: A case study from India. International Journal of Technology Management \& Sustainable Development, 10(1).

Dawson, P., and Daniel, L. 2010. Understanding SI: A provisional framework. International Journal of Technology Management, 51(1), pp. 9-21.

Dees, J.G. 1998. Enterprising Non-profits, Harvard Business Review, 76 (1), pp. 55-67.

De Muro, P., Hamdouch, A., Cameron, S., and Moulaert, F. 2007. Organisations de la société civile, innovation sociale et gouvernance de la lutte contre la pauvreté dans le Tiers-Monde. Mondes en Développement 3(139), pp. 25-42.

Denicolai, S., Ramirez, M., and Tidd, J. 2014. Creating and capturing value from external knowledge: the moderating role of knowledge intensity. $R \& D$ Management, 44(3), pp. 248264.

Denzin, N., and Lincoln, Y. 2000. Handbook of Qualitative Research, 2nd edition, Sage Publications, CA.

De', R. 2009. Economic Impact of Free and Open Source Software: A Study in India. Indian Institute of Management, Bangalore.

Díaz Andrade, A., and Urquhart, C. 2009. ICTs as a Tool for Cultural Dominance: Prospects for a Two Way Street, Electronic Journal of Information Systems in Developing Countries, 37(2), pp. 1-12.

Diener, E., and Suh, E. 1997. Measuring quality of life: Economic, social and subjective indicators. Social Indicators Research, 40, pp. 189-216.

Drucker, P. F. 1985. Innovation and Entrepreneurship: Practice and Principles, Harper \& Row: New York, 19-33.

Eggleston, K., Jensen, R., and Zeckhauser, R. 2002. Information and Communication Technologies, Markets, and Economic Development. The Global Information Technology Report: Readiness for the Networked World. New York, Oxford University Press, pp. 62-75.

Eisenhardt, K. 1989. Building theories from case study research, Academic Management Review, 14(4), pp. 532-550.

Foster, C., and Heeks, R. 2013. Innovation and scaling of ICT for the bottom-of- the-pyramid. Journal of Information Technology, 28(4), pp. 296-315.

Free Software Foundation, 2015. What is Free Software? Available at http://www.fsf.org/about/what-is-free-software, [Accessed 20 $0^{\text {th }}$ August, 2015] 
Galindo, M. and Méndez, M. T. 2014. Entrepreneurship, economic growth, and innovation: Are feedback effects at work? Journal of Business Research, May, pp. 825-829.

Graddy-Reed, A., and Feldman, M. P. 2015. Stepping up: an empirical analysis of the role of social innovation in response to an economic recession. Cambridge Journal of Regions, Economy and Society, 8(2), pp. 293-312.

Hall, J., Matos, S., and Martin, M. 2014. Innovation pathways at the Base of the Pyramid: establishing technological legitimacy through social attributes. Technovation, 34(5-6), pp. 265-269.

Heeks, R., and Kenny, C. 2002. ICTs and Development: Convergence or Divergence for Developing Countries? Proceedings of the 7th International Working Conference of IFIP WG9.4, Bangalore, India

Heeks, R. 2008. ICT4D 2.0: The Next Phase of Applying ICT for International Development. Computer, 41(6), pp. 26-33.

Heeks, R. 2010. Do Information and Communication Technologies (ICTs) Contribute to Development. Journal of International Development, 22, pp. 625-640.

Heeks, R., and Arun, S. 2010. Social outsourcing as a development tool: The impact of outsourcing IT services to women's social enterprises in Kerala, Journal of International Development, 22(4), pp. 441-454.

Heeks, R., 2012. Deriving an ICT4D research agenda: a commentary on 'Information and communication technologies for development (ICT4D): solutions seeking problems?' Journal of Information Technology, 27, 339-341.

Heeks, R. and Foster, C., 2013. Innovation and scaling of ICT for the bottom-of-thepyramid. Journal of Information Technology, 28(4).

Hibbert, S., Hogg, G., and Quinn, T., 2002. Consumer response to social entrepreneurship: the case of The Big Issue in Scotland. International Journal of Nonprofit and Voluntary Sector Marketing, 7, pp. 288-301.

Hippel, E. v. 1986. Lead Users: A Source of Novel Product Concepts, Management Science, 32(7), pp. 791-805.

Hippel, E. v., and Krogh, G. V. 2003. Open Source Software and the 'Private-Collective' Innovation Model: Issues for Organisation Science, Organisation Science, 14(2), pp. 209-223.

Hippel, E. v. 2005. Democratizing Innovation. Cambridge, MA: MIT Press.

Hochgerner, J. 2009. Innovation processes in the dynamics of social change. In: Loudin, J., Schuch, K., (Eds.), Innovation cultures. Challenge and learning strategy. Filosofia, Prague, pp. 17-45.

Howaldt, J., and Schwarz, M. 2010. Social Innovation: Concepts, research fields and international trends. Report of ESF, EU, and Aachen University, Dortmund.

Hubert, A., 2010. Empowering people, driving change: SI in the European Union. At: <http://ec.europa.eu/bepa/pdf/publications_pdf/social_innovation.pdf> (last accessed 19.12.2013). 
Hubert, A. 2011. Investing in social innovation. In: Andor, L., et al. (Ed.), Report Challenge Europe $\mathrm{N}^{\circ} 21$. Growth, well-being and social policy in Europe: Trade-off or synergy? European Policy Center, Brussels, pp. 34-39.

ITU, International Telecommunication Union. 2013. Measuring the Information Society. Geneva, Switzerland.

Izsak, K., and Griniece, E. 2012. Innovation Policy in 2012 - Challenges, trends and responses (produced under the Specific Contract for the Integration of the INNO Policy TrendChart with ERAWATCH (2011-2012). European Commission, Brussels.

Kenny, C. J. 2000. Expanding Internet access to the rural poor in Africa. Information Technology for Development 9(1), pp. 25-32.

Kilamo, T., Hammouda, I., Mikkonen, T. and Aaltonen, T. 2012. From proprietary to open source - growing an open source ecosystem. Journal of Systems and Software, 85, pp. 1467 1479.

Klein, H., and Myers, M. 1999. A Set of Principles for Conducting and Evaluating Interpretive Field Studies in Information Systems, MIS Quarterly, 23(1), pp. 67-93.

Klein, J. L., and Harrison, D., 2007. L'innovation sociale: Emergence et effets sur la transformation des sociétés'. Presses de l'Université du Québec, Québec City.

Lichtenthaler, U. 2011. Is open innovation a field of study or a communication barrier to theory development? A contribution to the current debate. Technovation, 31(1), pp. 138-139.

Madon, S. 2000. The internet and socio-economic development: Exploring the interaction. Information Technology \& People, 13(2).

Madon, S. 2005. Governance lessons from the experience of telecentres in Kerala. European Journal of Information Systems 14(4), pp. 401-416.

Madon, S., and Sharanappa, S. 2013. Social IT outsourcing and development: theorising the linkage, Information Systems Journal, 23(5), pp.381-399.

Mair, J., and Marti, I. 2006. Social entrepreneurship research: A source of explanation, prediction and delight, Journal of World Business, 41, pp. 36-44.

Maldonado, E. 2010. The process of introducing FLOSS in the public administration: the case of Venezuela. Journal of the Association for Information Systems, 11, pp. 756-783.

Mansell, R. 1999. Information and communication technologies for development: Assessing the potential and the risks. Telecommunications Policy, 23, pp. 35-50.

McDonald, R. 2007. An investigation of innovation in no-profit organizations: the role of organizational mission, Nonprofit and Voluntary Sector Quarterly, 36(2), pp. 256-281.

Miles, M. B., and Huberman, A. M. 1994. Qualitative Data Analysis: An Expanded Source Book. Sage Publications, Thousand Oaks, CA.

Moseson, A. J., Lama, L. and Tangorra, J. 2015. Development by Technology Seeding, Journal of International Development, 27(4), pp. 489-503. 
Moulaert, F., and Mehmood, A. 2010. Spaces of social innovation. In: Pike, A., RodriguezPose, A., Tomaney, J., (Eds.), A handbook of local and regional development, Routledge, London, pp. 212-225.

Mulgan, G. 2006. The Process of Social Innovation. Innovations Spring, pp. 145- 62. Nelson, R. R., Winter, S. G. 1982. An Evolutionary Theory of Economic Change. Cambridge, Massachusetts: The Belknap Press of Harvard University Press.

Nicholls, A., and Cho, A. H. 2006. Social entrepreneurship: The structuration of a field, in A. Nicholls (Ed.), Social Entrepreneurship: New Models of Sustainable Social Change, Oxford: Oxford University Press, 99-118.

Norris, P. 2001. Digital divide: Civic engagement, information poverty and the Internet world-wide. Cambridge, MA: Cambridge Univ. Press

OECD. 2007. Innovation and Growth: Rationale for an Innovation Strategy. Paris, France.

Ohlan, R. 2013. Pattern of Regional Disparities in Socio-economic Development in India: District Level Analysis, Social Indicators Research, 114(3), pp. 841-873.

Phills, J.A., Deiglmeier, K., and Miller, D. T. 2008. Rediscovering social innovation, Stanford Social Innovation Review, 6(4), pp. 34-43.

Pick, J. B., Gollakota, K., and Singh, M. 2014. Technology for Development: Understanding Influences on use of Rural Telecenters in India, Information technology for development, 20(4), pp. 296-323.

Pol, E., and Ville, S. 2009. Social innovation: Buzz word or enduring term? The Journal of Socio-Economics, 38, pp. 878-885.

Poon, D. 2011. The Emergence and Development of Social Enterprise Sectors. At: <http://repository.upenn.edu/sire/8/> (last accessed 19.12.2013).

Postner , L., Burdge, D., Jackson, S., Ellis, H., Hislop, G., and Goggins, S. 2015. Using humanitarian free and open source software (HFOSS) to introduce computing for the social good. ACM SIGCAS Computers and Society, 45(2), pp. 35-35.

Prabhu, N. G. 1999. Social entrepreneurial leadership, Career Development International, 3 , pp. 140-145.

Prahalad, C. K., McCracken, P., McCracken, R. 2009. The new nature of innovation. Report for OECD, FOR A, Copenhagen.

Prakash, A., and De, R. 2007. Importance of development context in ICT4D projects. Information Technology \& People, 20(3), pp. $262-281$.

Prakash, A. 2015. E-Governance and Public Service Delivery at the Grassroots: A Study of ICT Use in Health and Nutrition Programs in India. Information Technology for Development, pp. 1-14.

Pykalainen, T., 2007. Model for profiting from software innovations in the new era in computing. Technovation, 27, 179-193.

Ramani, S., and Mukherjee, V. 2014. Can breakthrough innovations serve the poor (bop) and create reputational (CSR) value? Indian case studies. Technovation, 35(5-6), pp. 295-305. 
Reed, R., Storrud-Barnes, S. and Jessup, L. 2012. How open innovation affects the drivers of competitive advantage. Management Decision, 50(1), pp. 58-73.

Reed, M. 2006. e-Governance and free software: how they are changing developing countries, UNU International Institute for Software Technology Panel Report, Event, NY, USA.

Sen, P., 2007. Ashoka's big idea: Transforming the world through social entrepreneurship, Futures, 39, pp. 534-553.

Sen, A. K., 1999. Development as Freedom, New York: Alfred A. Knopf, Inc.

Silvestre, B., and Silva Neto, R. 2014. Capability accumulation, innovation, and technology diffusion: lessons from a Base of the Pyramid cluster. Technovation, 34(5-6), pp. 270-283.

SSIR (Stanford Social Innovation Review), 2013. Social Innovation Creates Prosperous Societies. Summer.

Stake, R. 1995. The Art of Case Study Research. Sage Publications, Thousand Oaks, CA. Stallman, R. 1999. In: DiBona, C., Ockman, S., Stone, M., (Eds.), The GNU Operating System and the Free Software Movement. O'Reilly \& Associates, Inc, Sebastopol, CA, USA.

Strauss, A., and Corbin, J. 1990. Basics of qualitative research: Grounded theory procedures and techniques. Sage Publications, Newbury Park, CA.

Stryszowski, P. 2009. Innovation in the Software Sector. OECD Publishing, Paris.

Sunday, S. C., Duan, Y., and Chen, H. 2014. Examining emerging ICT's adoption in SMEs from a dynamic process approach, Information Technology \& People, 27(1), pp. $63-82$.

Tan, W.L., Williams, J., and Tan, T.M., 2005. Defining the 'Social' in 'Social Entrepreneurship': Altruism and Entrepreneurship, International Entrepreneurship and Management Journal, 1, 353-365.

Toffler, A., 1980. The Third Wave. Bantam Books: NY.

UNCTAD [United Nations Conference on Trade and Development]. 2012. Information Economy Report 2012: The Software Industry and Developing Countries. Geneva, Switzerland.

Van de Ven, A. H., and Poole, M. S. 1990. Methods for studying innovation development in the Minnesota Innovation Research Program, Organization Science, 1(3), pp. 313-335.

Vienna Declaration. 2011. Conference challenge social innovation. At:

<http://www.socialinnovation2011.eu/wp-content/uploads/2011/09/Vienna-

Declaration_final_10Nov2011.pdf> (last accessed 19.12.2013).

Walsham, G. 2001. Making a World of Difference: IT in a Global Context, Chichester: Wiley.

Weber, S. 2003. Open Source Software in Developing Economies. UN-ITU World Summit on the Information Society, Geneva.

Weerawarana, S., and Weeratunga, J. 2004. Open Source in Developing Countries, SIDA (Swedish International Development Cooperation Agency) Report. Stockholm, Sweden.

West, J., and Lakhani, K. R. 2008. Getting Clear About Communities in Open Innovation, Industry \& Innovation, 15(2), pp. 223-231. 
WBI [World Bank Institute]. 2009. Information and Communications for Development: Extending Research and Increasing Impact. Washington, DC. Available at:

https://openknowledge.worldbank.org/handle/10986/2636 (last accessed 14.04.2015)

Wolfe, R.A. 1994. Organizational innovation: review, critique and suggested research directions, Journal of Management Studies, 31(3), pp. 405-431.

Yildirim, N., and Ansal, H. 2011. Foresighting FLOSS (free/libre/open source software) from a developing country perspective: The case of Turkey. Technovation, 31, pp. 666-678.

Yin, R. 2009. Case Study Research: Design and Methods, Fourth Edition. Sage Publications, Thousand Oaks, CA.

Zahra, S. A., Gedajlovic, E., Neubaum, D. O., and Shulman, J. M. 2009. A typology of social entrepreneurs: Motives, search processes and ethical challenges, Journal of Business Venturing, 24(5), pp. 519-532.

Zamani-Miandashti, N., Pezeshki-Rad, G. and Pariab ,J. 2014. The influence of telecenters on rural life and their success correlates: lessons from a case study in Iran. Technovation, 334(56), pp. 306-314.

Zavatta R. 2008. Financing Technology Entrepreneurs \& SMEs in Developing Countries: Challenges and Opportunities. World Bank, Washington, D.C. 
Table 1: Profile of Interviewees

\begin{tabular}{|l|l|}
\hline $\begin{array}{l}\text { Interview } \\
\text { No. }\end{array}$ & Role \\
\hline M1 & Chief Technology Officer \\
\hline M2 & Chief Design Officer \\
\hline M3 & Founder-Director \\
\hline M4 & Director 1 \\
\hline M5 & Business Development Manager \\
\hline M6 & Director 1 \\
\hline M7 & Founder-Director \\
\hline M8 & Social data and analysis lead 1 \\
\hline M9 & Social data and analysis lead 2 \\
\hline
\end{tabular}

